\title{
Uncoupling protein 2 regulates reactive oxygen species formation in islets and influences susceptibility to diabetogenic action of streptozotocin
}

\author{
Simon C Lee*, Christine A Robson-Doucette* and Michael B Wheeler \\ Departments of Physiology and Medicine, University of Toronto, 1 King's College Circle (Room 3352), Toronto, Ontario, Canada M5S 1A8 \\ (Correspondence should be addressed to M B Wheeler; Email: michael.wheeler@utoronto.ca) \\ *(S C Lee and C A Robson-Doucette contributed equally to this work)
}

\begin{abstract}
Currently, the physiological function of uncoupling protein-2 (UCP2) in pancreatic islets and its role in the development of diabetes is a matter of great debate. To further investigate the impact of UCP2 on diabetes development, we used streptozotocin (STZ) to experimentally generate diabetes in both wild-type (WT) and UCP2-knockout (UCP2KO) mice. While multiple low-dose STZ injections led to hyperglycemia development over a 14-day period in both WT and UCP2KO mice, we found the development of hyperglycemia to be significantly less severe in the UCP2KO mice. Measurement of insulin and glucagon secretion (in vitro), as well as their plasma concentrations (in vivo), indicated that UCP2-deficiency showed enhanced insulin
\end{abstract}

secretion but impaired $\boldsymbol{\alpha}$-cell function. Glucagon secretion was attenuated, despite reduced insulin secretion after exposure to STZ, which together contributed to less severe hyperglycemia development in UCP2KO mice. Further experimentation revealed that UCP2-deficient $\alpha_{-}$and $\beta$-cells had chronically higher cellular reactive oxygen species (ROS) levels than the WT prior to STZ application, which correlated with increased basal $\beta$ - and $\alpha$-cell mass. Overall, we suggest that increased chronic ROS signaling as a result of UCP2-deficiency contributes to enhanced $\beta$-cell function and impairment of $\boldsymbol{\alpha}$-cell function, leading to an attenuation of STZ-induced hyperglycemia development.

Journal of Endocrinology (2009) 203, 33-43

\section{Introduction}

Blood glucose homeostasis is maintained by the concerted and opposing actions of the hormones insulin and glucagon. Insulin release from the pancreatic $\beta$-cell promotes glucose utilization when blood glucose levels are high, while glucagon release from the $\alpha$-cell triggers glucose secretion when blood glucose levels are low. Glucose metabolism represents a key process linking glucose-sensing and the modulation of insulin release from the $\beta$-cell. Energy from glucose breakdown is initially used to develop a proton gradient across the inner mitochondrial membrane called the proton motive force, which drives ATP synthesis. Accumulation of ATP forces $\mathrm{K}_{\text {ATP }}$ channel closure and subsequent cellular depolarization, which prompts the release of insulin.

An inner mitochondrial protein known as uncoupling protein-2 (UCP2), is shown to be expressed in pancreatic $\beta$-cells (Chan et al. 1999) and $\alpha$-cells (Diao et al. 2008), as well as other tissues (Fleury et al. 1997) and has been shown to contribute to mitochondrial proton leakage (Fink et al. 2002, Affourtit \& Brand 2008). In the $\beta$-cell, such activity may uncouple glucose metabolism from ATP synthesis thereby impeding the mechanism that triggers insulin secretion. A number of reports have identified UCP2 as a participant in diabetes and $\beta$-cell dysfunction, and UCP2 has been specifically shown to negatively regulate insulin secretion (Chan et al. 1999, 2001, Zhang et al. 2001, Joseph et al. 2002). These studies demonstrate a relationship between UCP2 over-activity and insulin secretion deficiencies, while also revealing that UCP2 deficiency could improve $\beta$-cell function in animal models of obesity and type- 2 diabetes. However, it must be noted that a recent study by Pi et al. (2009) presented opposing results with their strains of UCP2knockout (UCP2KO) mice, showing impaired insulin secretion after successive backcrossing onto other strains of mice. This interesting study has highlighted potential differences in the two independently produced UCP2 - / mouse models. In particular, the authors have reported that genetic background effects may have influenced previous studies linking the UCP2-null mouse model and enhanced insulin secretion. UCP2 expression has also recently been observed in the pancreatic $\alpha$-cell, though less is known about its specific function in these cells. However, UCP2 has been 
attributed to dysregulation of glucagon secretion and decreased cell viability (Diao et al. 2008). In the $\alpha$-cell, ATP-sensitive potassium channels may also play a role in regulating electrical activity and glucagon release (Gromada et al. 2004, MacDonald et al. 2007) and could be affected by the activity of UCP2. Therefore, UCP2 ablation from the $\boldsymbol{\alpha}$-cell may serve to disrupt normal secretion patterns.

In addition to its impact on hormone secretion, UCP2 has been functionally linked to the limitation of reactive oxygen species (ROS) formation (Negre-Salvayre et al. 1997, Arsenijevic et al. 2000) and has shown to be strongly induced by superoxide (Echtay et al. 2002) and the lipid peroxidation by product 4-hydroxy-2-nonenal (Echtay et al. 2003). Such upregulation of uncoupling activity suggests that UCP2 is involved in a feedback response to ROS and may serve as a means for its control. Under diabetic conditions, oxidative stress plays an important role in the development of pancreatic islet cell dysfunction and deterioration. Patients with diabetes have been shown to exhibit signs of chronic oxidative stress, with elevated levels of oxidants (Nourooz-Zadeh et al. 1995) and markers of oxidative tissue damage (Gopaul et al. 1995, Rehman et al. 1999). The pancreatic $\beta$-cell is a prime target of oxidative stress-mediated effects, where oxidants have been shown to negatively affect mitochondrial action and insulin secretion (Maechler et al. 1999). The susceptibility of $\beta$-cells to oxidative stress may be attributed to their lower intrinsic antioxidant enzyme capacity in comparison to other metabolically active tissues (Grankvist et al. 1981, Malaisse et al. 1982, Lenzen et al. 1996, Tiedge et al. 1997). Due to the potential vulnerability of islets to oxidative stress, it is likely that slight alterations in the redox balance of this tissue may translate into significant functional changes. However, it remains uncertain to what extent UCP2dependent modulation of oxidative stress may contribute to islet function and viability.

Streptozotocin (STZ) has been widely used to experimentally induce diabetes in animal systems (Rakieten et al. 1963, Lenzen 2008) via selective necrosis of $\beta$-cells. In the present study using multiple low-dose STZ (MLDS) injections to investigate the impact of UCP2 on the development of STZinduced diabetes in vivo, we show that UCP2-deficient mice (UCP2KO) developed lesser hyperglycemia than their wildtype (WT) counterparts. Further investigation revealed that knockout of UCP2 resulted in higher basal cellular ROS formation in both $\alpha$ - and $\beta$-cells, which correlated with increased relative $\beta$ - and $\alpha$-cell mass, suggesting altered proliferative signaling pathways. We also found that after STZ-administration, $\boldsymbol{\alpha}$-cell function in the UCP2KO mouse was impaired compared with WT, despite reduced insulin secretion and hence reduced possible paracrine inhibition by the $\beta$-cell. Overall, we suggest that UCP2 plays an important role in the maintenance of $\alpha$-cell function and that the basal level of ROS and/or ROS-associated signaling plays an important role in $\alpha$-cell function.

\section{Materials and Methods}

\section{Animals}

Male, 6- to 8-week old WT and UCP2KO littermate mice were used in this study. UCP2KO mice were previously generated on a C57BL6/129 mixed background as previously described (Zhang et al. 2001). WT and UCP2KO mice were raised in a colony at the University of Toronto where all animal protocols were approved by the Animal Care Committee at the University of Toronto and all animals were handled according to the guidelines of the Canadian Council of Animal Care.

\section{Chemicals and reagents}

STZ ( $N$-(methylnitrosocarbamoyl)- $\boldsymbol{\alpha}$-D-glucosamine) was obtained from Sigma-Aldrich. Insulin ELISA kits were obtained from Crystal Chem, Inc (Downers Grove, IL, USA). Materials for glucagon RIA were obtained from Linco Research, Inc (St Charles, MO, USA). Dichlorofluorescein (DCF) diacetate was obtained from Invitrogen. Antibodies for insulin were obtained from Biomeda (Foster City, CA, USA) and glucagon from Vision Biosystems, Inc (Norwell, MA, USA).

\section{STZ-induced diabetes}

Mice were treated with MLDS (40 $\mu \mathrm{g}$ of STZ/g body mass) via i.p. injection. Each mouse received a single daily injection of STZ for five consecutive days. Control animals were handled identically, but injected with vehicle (citrate buffer) only. Mice were maintained for 14 days after the start of treatment to allow animals to reach and surpass the peak incidence of $\beta$-cell apoptosis, which occurs at approximately day 11 when insulitis is maximal (O'Brien et al. 1996). Mice were fed ad libitum over this time. Periodic body mass and tail blood glucose measurements were recorded every 2-3 days to track weight changes and the development of hyperglycemia. Mice were killed on day 14 , and tissues were harvested for further analyses.

\section{Plasma insulin and glucagon concentration measurements}

Blood samples were collected from animals at the time of killing and collected in heparin-coated tubes. Plasma was separated from whole blood by centrifugation at a relative force of $1305 \mathrm{~g}$. Plasma insulin concentrations were assayed using an ELISA kit (Crystal Chem, Inc.) according to the manufacturer's instructions. Plasma glucagon concentrations were assayed using a glucagon RIA kit (Linco Research, Inc.) according to the manufacturer's instructions.

\section{Pancreatic islet morphology: $\beta$ - and $\alpha$-cell mass}

Pancreatic islet morphology was analyzed as described previously (Asghar et al. 2006). Briefly, mouse pancreata were surgically isolated at the end of the 14-day study and 
fixed in 10\% neutral buffered formalin solution for $48 \mathrm{~h}$. Following fixation, samples were embedded in paraffin and histological sections were prepared from each pancreas and placed on slides. Sections were treated with pepsin and incubated for $1 \mathrm{~h}$ in either rabbit polyclonal anti-insulin (1:200 dilution; Biomeda) or rabbit polyclonal anti-glucagon at 1:150 dilution (Vision Biosystems, Inc). Sections were counterstained with hematoxylin. For quantification, slides were digitized on a bright-field scanner at $20 \times$ magnification. Quantitative analysis of staining area was performed with ImageScope software (Aperio Technologies, Vista, CA, USA) using the positive-pixel count algorithm. Results were normalized to whole slice area.

\section{Pancreatic islet isolation, culture and dispersal}

Isolated mouse pancreatic islets were used for in vitro investigation of ROS measurements. Mice were anesthetized with $250 \mathrm{mg} / \mathrm{kg}$ tribromoethanol via i.p. injection. The pancreas was perfused via the common bile duct with collagenase type-V $(0.8 \mathrm{mg} / \mathrm{ml})$ in RPMI-1640 solution supplemented with $2 \%$ BSA. Pancreata were digested at $37^{\circ} \mathrm{C}$ for 16-20 min and islets were mechanically separated from debris tissue and cultured in RPMI-1640 media supplemented with $11.1 \mathrm{mM}$ glucose, $10 \%$ fetal bovine serum, $100 \mathrm{U} / \mathrm{ml}$ penicillin, and $100 \mathrm{mg} / \mathrm{ml}$ streptomycin. Islets were cultured overnight at $37^{\circ} \mathrm{C}$ prior to treatments and recordings. Dispersed islet cells were also used for experimentation. Isolated islets were washed in PBS supplemented with $2 \mathrm{mM}$ EGTA. Islets were dissociated into their constituent cells by digestion in the neutral protease Dispase-II (Roche Applied Science) for $6 \mathrm{~min}$ at $37^{\circ} \mathrm{C}$, followed by mild pipetting to facilitate separation of cells. The digestion was halted by the addition of RPMI-1640 media supplemented with $10 \%$ fetal bovine serum. Dispersed cells were washed with fresh islet culture media and plated onto glass cover slips coated with poly-L-lysine and maintained at $37^{\circ} \mathrm{C}$.

\section{In vitro hormone secretion assays}

Insulin and glucagon secretion assays were performed as previously described (Diao et al. 2005). Briefly, isolated pancreatic islets from WT and UCP2KO mice were cultured in RPMI-1640 media supplemented with $11 \cdot 1 \mathrm{mM}$ glucose and either $100 \mu \mathrm{M} \mathrm{STZ}$ or vehicle for $16 \mathrm{~h}$. Immediately prior to secretion studies, islets were placed in $\mathrm{KRBH}$ solution and pre-incubated at $2.8 \mathrm{mM}$ glucose for $1 \mathrm{~h}$ (insulin assay) or $16.7 \mathrm{mM}$ glucose for $15 \mathrm{~min}$ (glucagon assay). Islets were subsequently transferred into fresh buffer containing either high $(16.7 \mathrm{mM})$ or low $(2.8 \mathrm{mM})$ glucose concentrations and incubated for $1 \mathrm{~h}$ at $37^{\circ} \mathrm{C}$. Supernatant was collected and assayed for insulin or glucagon using RIA kits (Linco Research). Approximately 60-90 islets were used per condition (15 islets per tube) in each independent experiment.
Measurement of ROS by fluorescence microscopy

ROS measurements were performed using the hydrogen peroxide $\left(\mathrm{H}_{2} \mathrm{O}_{2}\right)$-sensitive dye DCF. For whole pancreatic islets treated with STZ, islets were isolated as described above and incubated in $100 \mu \mathrm{M} \mathrm{STZ}$ for $16 \mathrm{~h}$ prior to addition of DCF in RPMI-1640 media supplemented with 10\% fetal bovine serum and $11 \mathrm{mM}$ glucose. Incubations were performed at $37^{\circ} \mathrm{C}$ and $5 \% \mathrm{CO}_{2}-95 \%$ air. Whole pancreatic islets or dispersed islets attached to glass cover slips were loaded with $5 \mu \mathrm{M}$ DCF for $45 \mathrm{~min}$ in buffer solution $\left(130 \mathrm{mM} \mathrm{NaCl}, 5 \mathrm{mM} \mathrm{KCl}, 2 \mathrm{mM} \mathrm{CaCl}, 1 \mathrm{mM} \mathrm{MgCl}{ }_{2}\right.$, $5 \mathrm{mM} \mathrm{NaHCO} 3$, and $10 \mathrm{mM}$ HEPES at $\mathrm{pH} \mathrm{7.4)}$ and transferred to an open chamber with buffer solution, placed on the microscope stage, and were maintained at $37^{\circ} \mathrm{C}$ using a Delta $\mathrm{T}_{4}$ Culture Dish Controller (Bioptechs, Butler, PA, USA). Fluorescent excitation was achieved at $480 \mathrm{~nm}$ for $300 \mathrm{~ms}$, and emission was detected with a $525 \mathrm{~nm}$ band pass filter using a $505 \mathrm{~nm}$ beam splitter. Fluorescence intensity levels were maintained within the upper and lower detection thresholds of the recording equipment. Experiments were carried out using an Olympus BX51W1 fluorescent microscope fitted with a $20 \times / 0.95$ water immersion objective and a cooled CCD camera equipped with a magnification changer (U-TVCAC, Olympus Canada Inc., Markham, ON, Canada). A xenon lamp-based DeltaRam high-speed monochromator (Photon Technology International, Birmingham, NJ, USA) was used for excitation. Control of the monochromator and video camera, as well as fluorescent data collection and analysis, were performed using ImageMaster 3 software (Photon Technology International).

\section{Statistical analysis}

The data are expressed as mean \pm S.E.M. where applicable. Significance was determined using Student's $t$-test or one-way ANOVA with Tukey-Kramer or Dunn's multiple comparisons post test where appropriate. $P<0.05$ was considered statistically significant.

\section{Results}

\section{Impact of UCP2 on the development of hyperglycemia in} STZ-treated mice

MLDS injections (daily i.p. injection of $40 \mu \mathrm{g}$ STZ/g body mass for five consecutive days) were used to experimentally generate diabetes in mice in vivo. WT and UCP2KO were compared to determine how the absence of UCP2 affects the development of hyperglycemia. Blood glucose was measured periodically to monitor the development of the STZ-induced hyperglycemia (Fig. 1A). Both control (citrate buffer only) groups displayed consistent blood glucose homeostasis over the 14-day study period and did not show any significant difference or change in blood glucose concentration 

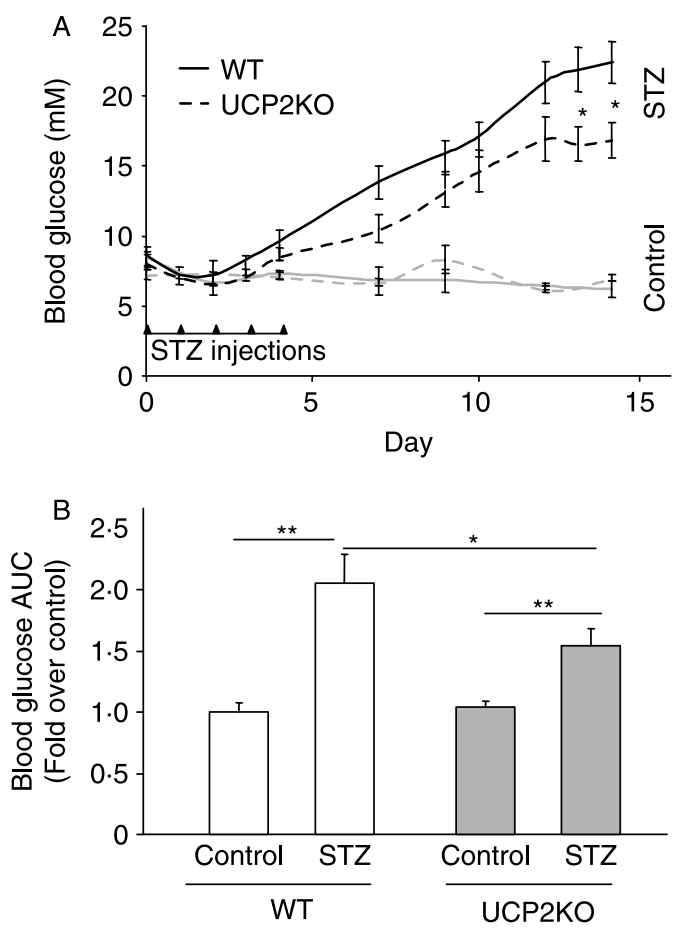

Figure 1 Effect of UCP2 on STZ-induced hyperglycemia. (A) WT and UCP2KO mice were treated with either control vehicle ( $n=6$ mice per group) or STZ $(n=8)$, at a daily dose of $40 \mu \mathrm{g} / \mathrm{g}$ body weight for five consecutive days. Blood glucose values were measured periodically over a 14-day period until they were killed. Mean blood glucose values are plotted for each group as shown. (B) AUC assessment of the blood glucose curves in A. Values were normalized to WT control and expressed as fold change. ${ }^{*} P<0 \cdot 05$; ${ }^{* *} P<0 \cdot 01$.

compared to their starting values $(8 \cdot 4 \pm 0 \cdot 81 \mathrm{mM}$ glucose for WT and $7 \cdot 2 \pm 0 \cdot 39 \mathrm{mM}$ glucose for UCP2KO). After MLDS administration, hyperglycemia became discernable after 4 days in both WT and UCP2KO mice, progressively increasing in both groups for the length of the study. However, after day 12, STZ-treated UCP2KO mice showed significantly lower hyperglycemia development when compared to WT mice. Area under the curve quantification of the 14-day blood glucose curves revealed a 2.06-fold increase in hyperglycemia in the STZ-treated WT, when compared with the control mice, whereas STZ-treated UCP2KO showed a $1 \cdot 58$-fold increase compared to their respective control mice (Fig. 1B). Together, these data suggest that UCP2KO mice develop less hyperglycemia when induced by STZ, possibly resulting from differences in $\beta$ - and/or $\alpha$-cell function or survivability as a result of UCP2KO. It is important to note that the observed differences in hyperglycemia development were not the result of differences in body mass between the WT and UCP2KO groups. Body mass values were recorded both at the beginning of the experiment as well as at the end of the study and no significant differences were observed between the two groups at either time point (data not shown).
Impact of UCP2 on $\alpha$ - and $\beta$-cell mass after STZ treatment

It was previously reported that $\beta$-cell mass was increased in UCP2KO mice, most notably after exposure to high-fat diet (Joseph et al. 2002). In the STZ-induced diabetes model, loss of $\beta$-cell mass is a principal outcome of $\beta$-cell cytotoxicity, and is a key determinant in the loss of glycemic control (Lenzen 2008). Relative $\beta$-cell area was determined by immunohistochemical analysis using insulin immunostaining of pancreatic slices. Representative images (Fig. 2A) show decreased and disrupted patterns of insulin staining in the islets of STZ-treated animals. Quantification of the insulinpositive staining area (normalized to entire pancreatic slice area) was used to gage $\beta$-cell area (Fig. $2 \mathrm{~B}$ ). While MLDS treatment decreased $\beta$-cell area in both genotypes as expected, no significant difference was observed when the STZ-induced decrease in $\beta$-cell area was compared between WT and UCP2KO animals (Fig. 2B). These findings suggest that the loss of $\beta$-cells as a result of STZ treatment is not influenced by the presence or absence of UCP2. However, comparison of control $\beta$-cell area between the two genotypes reveals that UCP2KO mice have a greater proportion of $\beta$-cells than the WT (Fig. 2B), which is consistent with previous findings (Joseph et al. 2002).
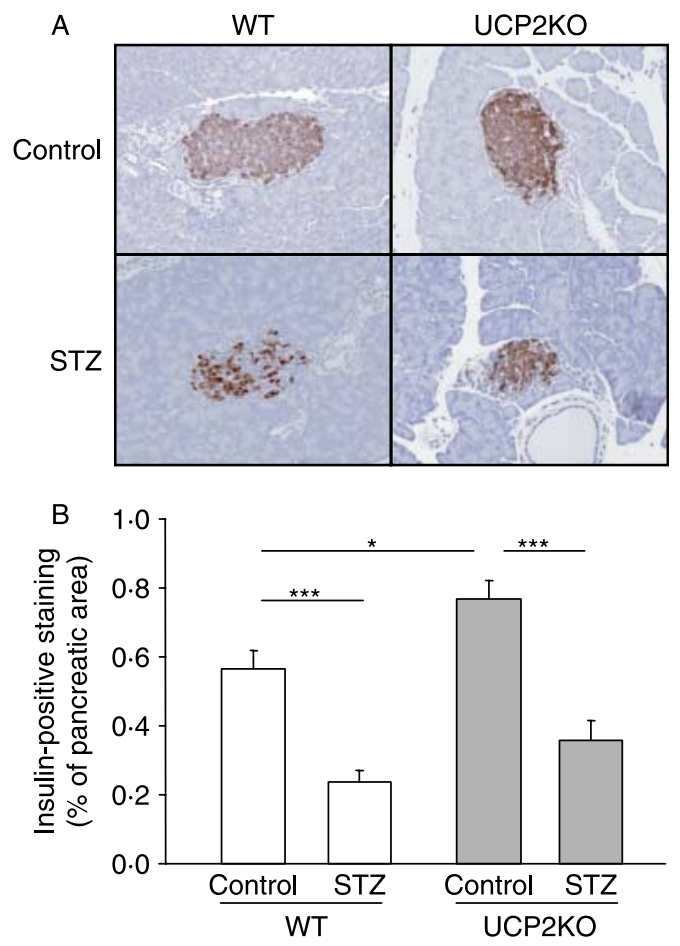

Figure 2 Effect of STZ treatment on $\beta$-cell area. Immunohistochemical analysis was performed on pancreatic sections prepared from control and STZ-treated WT and UCP2KO mice at 2 weeks post-treatment. Slices were stained for insulin to reveal presence of $\beta$-cells (representative crops of islets shown in A). Insulin staining area was quantified and normalized to total pancreatic slice area (B). $n=5 ;{ }^{*} P<0 \cdot 05 ;{ }^{* * *} P<0 \cdot 001$. 
Similar to the quantification of $\beta$-cell area, quantification of relative $\alpha$-cell area was also performed; however, in this case, glucagon-positive immunostaining was used. Representative images (Fig. 3A) show typical glucagon staining along the islet periphery in control animals. However, in STZ-treated animals there is a noticeable disruption of the staining pattern and $\alpha$-cell distribution. Interestingly, when $\alpha$-cell mass was quantified from the stained slices, we found that STZ treatment did not significantly alter the $\alpha$-cell area in the WT (Fig. 3B), despite the large increase in plasma glucagon observed in these animals after treatment with STZ (Fig. 4B). Surprisingly, UCP2KO mice displayed higher $\alpha$-cell area in both the untreated and STZ-treated conditions when compared with the WT animals (Fig. 3B), despite their similar levels of plasma glucagon (Fig. 4B). Similar to the WT mice, there was no significant change in $\alpha$-cell area after STZ treatment in the UCP2KO mice (Fig. 3B). These results suggest that while STZ does not appear to affect $\alpha$-cell numbers in either genotype, UCP2, or lack thereof, clearly has an impact on $\alpha$-cells in the control/untreated condition.
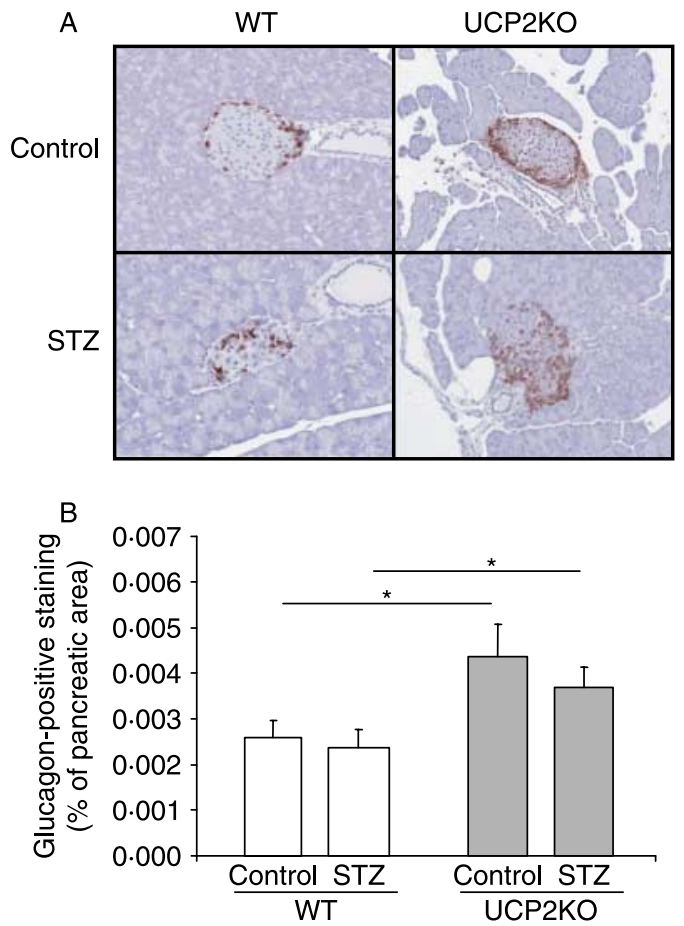

Figure 3 Effect of STZ treatment on $\alpha$-cell area. Immunohistochemical analysis was performed on pancreatic sections prepared from control and STZ-treated WT and UCP2KO mice at 2 weeks post-treatment. Slices were stained for glucagon to reveal presence of $\alpha$-cells (representative images of islets shown in A). Glucagon staining area was quantified and normalized to total pancreatic slice area. (B) $(n=5)$; $* P<0 \cdot 05$
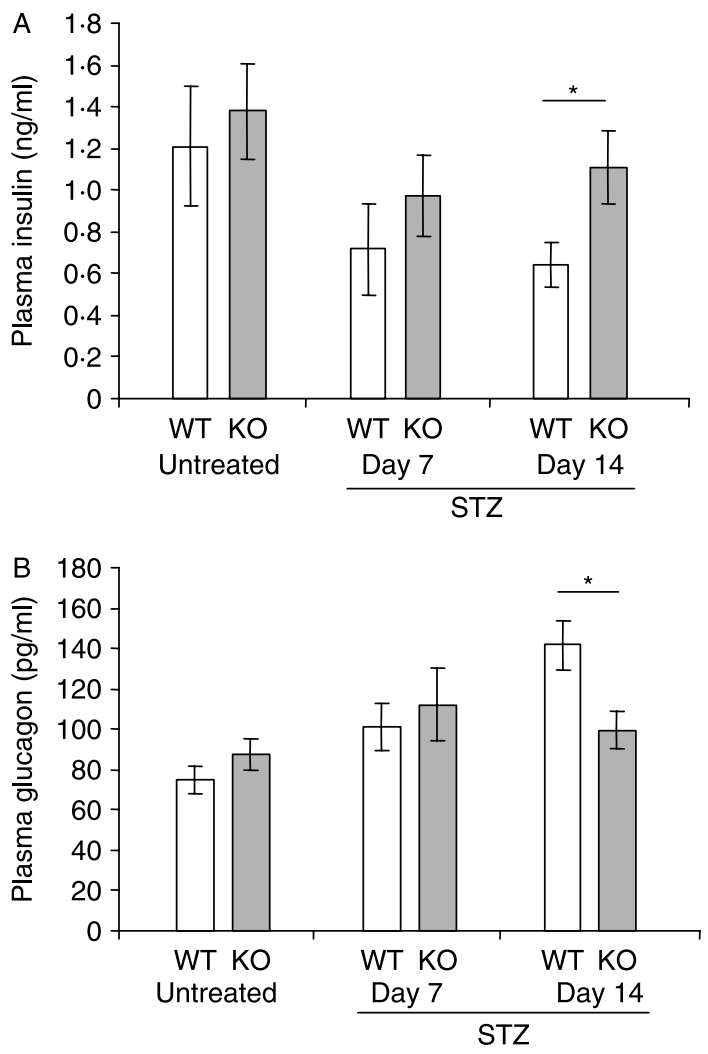

Figure 4 Effect of UCP2 and STZ on plasma islet hormone concentrations. (A) Blood was collected from control and STZ-treated mice at days 7 and 14 and plasma was extracted. Plasma was assayed for insulin content by ELISA $(n=5)$. (B) Glucagon levels were measured in the plasma samples by RIA $(n=5) .{ }^{*} P<0 \cdot 05$.

Impact of UCP2 on plasma hormone concentrations after MLDS treatment

To determine the impact of UCP2 on plasma insulin levels after MLDS, circulating plasma insulin levels were measured in both WT and UCP2KO animals at 7 and 14 days after MLDS injections. Measurement of plasma insulin concentrations showed similar values in both sets of control animals (insulin in $\mathrm{ng} / \mathrm{ml}$ : WT $1.23 \pm 0 \cdot 57$, UCP2KO $1 \cdot 38 \pm 0 \cdot 51$ ) indicating that basal plasma insulin levels were not significantly different (Fig. 4A). Following STZ treatment, insulin levels showed a downward shift and were significantly lower in WT than untreated controls, but the severity of the STZ effect was less pronounced in the UCP2KO group. As seen in Fig. 4A, UCP2KO mice showed significantly higher plasma insulin levels at day 14 than WT (insulin in ng/ml: UCP2KO $1 \cdot 01 \pm 0 \cdot 18$, WT $0 \cdot 66 \pm 0 \cdot 10, P<0 \cdot 05)$. These results suggest that $\mathrm{UCP} 2 \mathrm{KO}$ mice possess a superior ability to release insulin during $\beta$-cell insult by STZ, which correlates with their blunted hyperglycemia development compared to WT mice. 
Studies of STZ treatment in mice have shown that glucagon levels rise significantly after treatment (Dubuc 1987), possibly due to decreased paracrine inhibition of insulin on $\alpha$-cell function. Therefore, we further examined the effect of UCP2 deficiency on plasma glucagon levels after treatment with STZ (Fig. 4B). Similar to insulin, plasma glucagon was measured at 7 and 14 days after beginning STZ treatment. Comparison of glucagon levels in the WT and $\mathrm{UCP} 2 \mathrm{KO}$ control groups revealed no significant differences in their basal plasma glucagon $(74 \cdot 7 \pm 6 \cdot 9$ and $87 \cdot 5$ $\pm 8 \cdot 1 \mathrm{pg} / \mathrm{ml}$ respectively). In the WT animals, a significant increase in plasma glucagon level was observed after 14 days of STZ treatment $(141.6 \pm 11.9 \mathrm{pg} / \mathrm{ml}, P<0 \cdot 01)$, similar to that previously reported (Dubuc 1987). However, plasma glucagon levels in UCP2KO animals were significantly lower at day $14(99 \cdot 4 \pm 9 \cdot 1 \mathrm{pg} / \mathrm{ml}, P<0 \cdot 05)$ than those shown in the WT group (Fig. 4B).

\section{Impact of UCP2 on glucagon and insulin secretion}

Pancreatic islets were isolated from both WT and UCP2KO animals, and treated with STZ for $16 \mathrm{~h}$ before glucosecoupled insulin and glucagon secretion were measured in vitro. As expected, high glucose stimulated the secretion of insulin (Fig. 5A), whereas low glucose stimulated glucagon secretion (Fig. 5B) in WT control (untreated) islets. Interestingly, STZ treatment for $16 \mathrm{~h}$ did not significantly alter the level of insulin (Fig. 5A) or glucagon secretion (Fig. 5B) in WT islets. $\mathrm{UCP} 2 \mathrm{KO}$ control islets displayed significantly increased glucose-stimulated insulin secretion (GSIS) compared with the WT control (Fig. 5A). However, after STZ treatment, this level of insulin secretion was reduced to levels similar to WT islets (Fig. 5A). Conversely, glucagon secretion in the $\mathrm{UCP} 2 \mathrm{KO}$ control islets was significantly reduced compared with that of the WT control islets, with little or no increase observed after $16 \mathrm{~h}$ incubation with STZ (Fig. 5B).

\section{Impact of UCP2 on ROS production before and after STZ treatment}

It has been suggested that mild mitochondrial uncoupling via UCP2 function can help to ameliorate ROS formation (Negre-Salvayre et al. 1997, Arsenijevic et al. 2000). As such, we investigated the impact of UCP2 on STZ-induced ROS formation in vitro. To measure ROS production in $\beta$-cells, islets were dispersed into individual cells, attached to glass cover slips and treated with STZ for $16 \mathrm{~h}$ prior to imaging with the hydrogen-peroxide-sensitive fluorescent probe DCF. Large cells were selected as $\beta$-cells, as they are likely to be insulin-positive (Supplementary Fig. S1, available in the online version of the Journal of Endocrinology at http:// joe.endocrinology-journals.org/cgi/content/full/JOE-090117/DC1) and have been shown to be larger than other cell types (Göpel et al. 1999, Diao et al. 2008). In both WT and UCP2KO $\beta$-cells, we did not find a significant increase in ROS formation post-STZ treatment in either genotype;
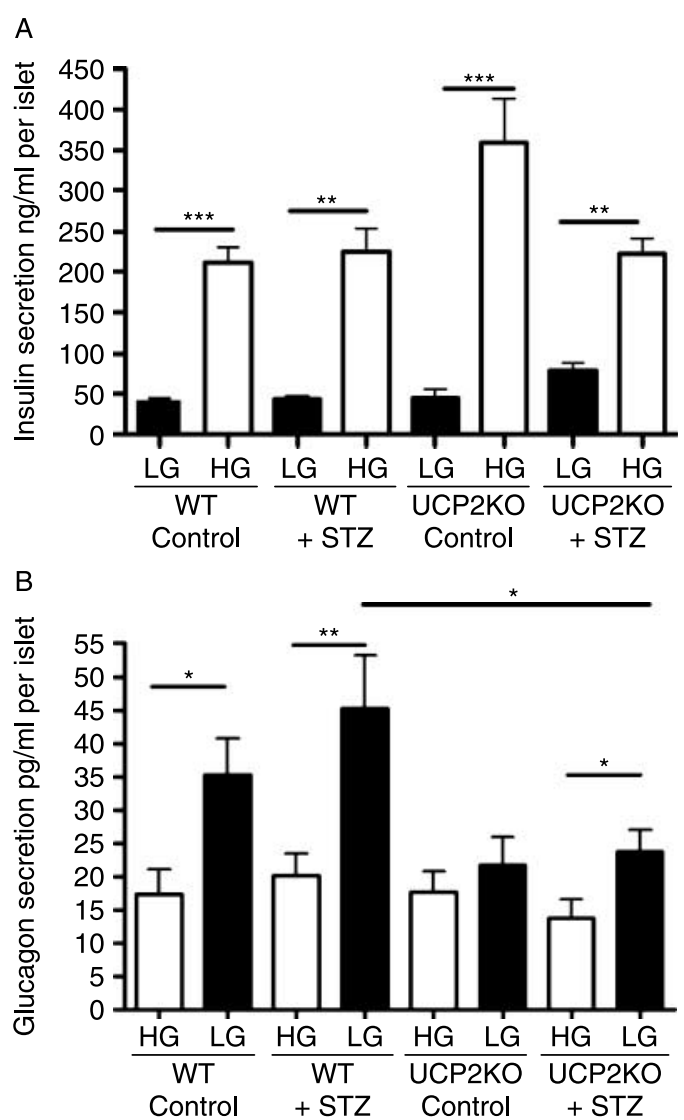

Figure 5 In vitro measurement of glucose-coupled hormone secretion. Islets were isolated from WT and UCP2KO mice, treated with STZ for $16 \mathrm{~h}$ (or left in buffer for $16 \mathrm{~h}$ in the case of the control), and used to measure glucose-stimulated insulin secretion (A) or glucose-stimulated glucagon secretion (B). Low glucose (LG) concentration used was $2 \cdot 8 \mathrm{mM}$; high glucose (HG) concentration used was $16 \mathrm{mM}$. Experiments were performed in triplicate. $n=3$. $* P<0 \cdot 05 ; * * P<0 \cdot 01 ; * * * P<0 \cdot 001$.

however, we did observe a significant increase in ROS formation when untreated WT and UCP2KO controls were compared (Fig. 6A), suggesting that knockout of UCP2 in the $\beta$-cell increases ROS formation in this cell type. To measure ROS in $\alpha$-cells, whole islets were isolated, treated with STZ for $16 \mathrm{~h}$ and then imaged with DCF. Using confocal microscopy, we discovered that the fluorescent DCF dye does not penetrate past the outer shell of cells in the islet (data not shown). The outer shell of the mouse islets is mainly comprised of $\boldsymbol{\alpha}$-cells (Gromada et al. 2007); as such, we are confident that these measurements are mainly of $\alpha$-cell ROS levels. In WT $\boldsymbol{\alpha}$-cells, treatment with STZ for $16 \mathrm{~h}$ resulted in a significant increase in DCF fluorescence, corresponding to elevated levels of ROS formation $(2 \cdot 72 \pm 0 \cdot 49$-fold over control, $P<0 \cdot 05$; Fig. 6B). Comparison of basal ROS levels (i.e. prior to STZ treatment) between the WT and the $\mathrm{UCP} 2 \mathrm{KO} \alpha$-cells revealed that UCP2KO $\alpha$-cells have significantly elevated basal ROS levels compared with that 
A
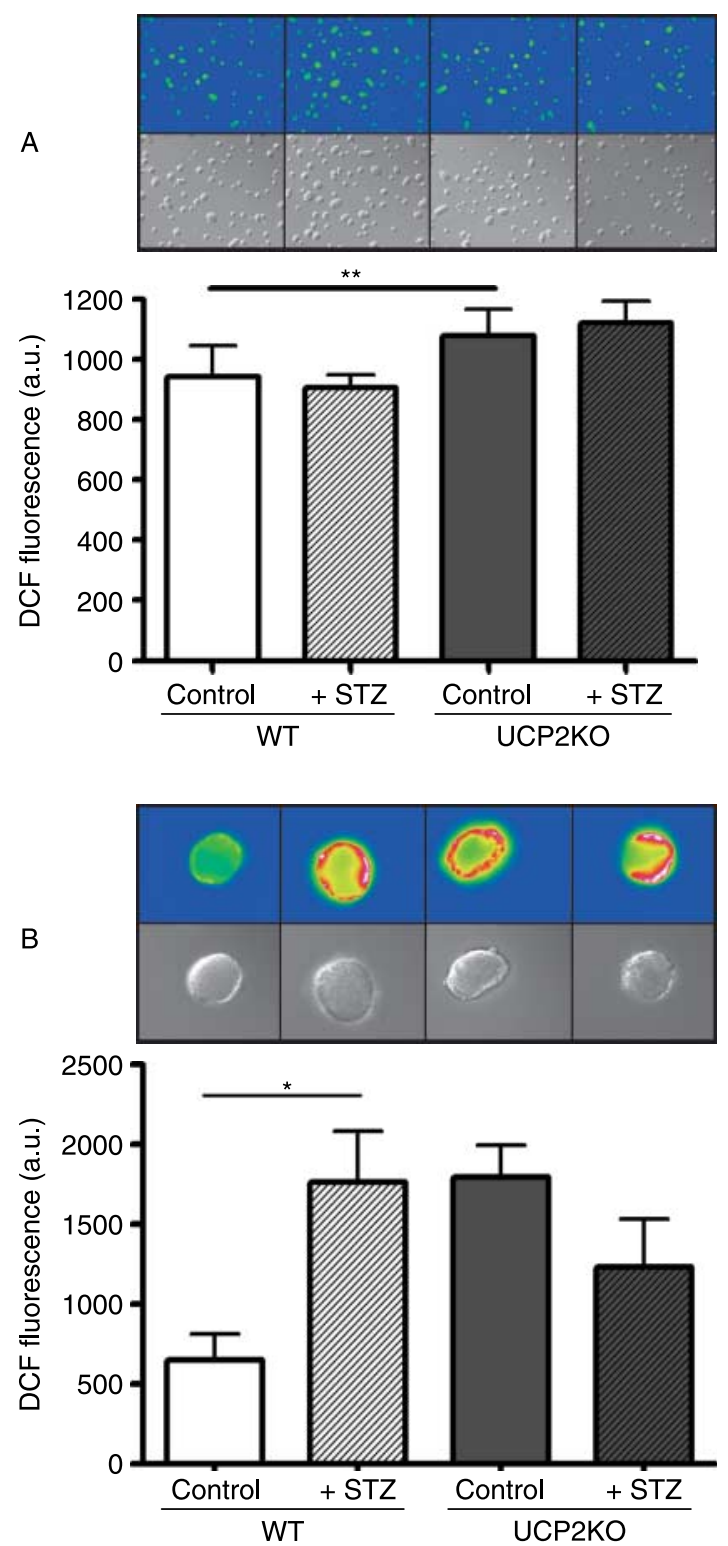

Figure 6 Measurement of ROS levels in $\alpha$ - and $\beta$-cells before and after STZ exposure. (A) Islets were dispersed into individual cells to release $\beta$-cells from the interior of the islets and plated onto glass cover slips. Cover slips were either treated with STZ or medium minus STZ (control group) for $16 \mathrm{~h}$. Cells were then imaged using the ROS-sensitive fluorescent dye DCF. Fluorescence intensity was quantified. $n=6 .{ }^{*} P<0 \cdot 05$. Images above the bar graph are representative fluorescent (top row) and light (bottom row) images. (B) To measure ROS in $\alpha$-cells, whole islets were isolated and cultured in medium containing $100 \mu \mathrm{M} \mathrm{STZ}$ for $16 \mathrm{~h}$. (Control, no STZ treatment). Islets were loaded with the ROS-sensitive fluorescent probe, DCF, and ROS levels quantified using a fluorescent microscope. $n=6 ; * P<0 \cdot 05$; Images above the bar graph are representative fluorescent (top row) and light (bottom row) images. of WT islets $(2 \cdot 77 \pm 0 \cdot 31$-fold over the WT; Fig. 6B). Surprisingly, no further increase in ROS was observed in UCP2KO islets treated with STZ (Fig. 6B). Additional measurements using the mitochondrial superoxide-specific probe mitoSOX revealed similar patterns which again showed elevated ROS in the UCP2KO islets (Supplementary Fig. S2, available in the online version of the Journal of Endocrinology at http://joe.endocrinology-journals.org/ cgi/content/full/JOE-09-0117/DC1).

\section{Discussion}

The impact of UCP2 on the development of STZ-induced diabetes: UCP $2 \mathrm{KO}$ mice are more resistant to hyperglycemia development

While UCP2 expression has been demonstrated to impact pancreatic islet function (Chan et al. 2001, Zhang et al. 2001, Joseph et al. 2002, 2004, De Souza et al. 2007), its role in the development of diabetes is still greatly debated. To further investigate the role of UCP2 in the development of diabetes, we treated both WT and UCP2KO mice with MLDS injections to experimentally induce diabetes. We found that MLDS injections induced hyperglycemia in WT mice, as expected over a 14-day period (Fig. 1). The UCP2KO mice also developed hyperglycemia; however, this was significantly less severe than the WT group (Fig. 1). Interestingly, this finding contradicts those of Emre et al. (2007a), who found that UCP2-null mice developed more severe and rapid hyperglycemia after MLDS administration (Emre et al. 2007a). Though the study of Emre et al. considered immune mechanisms, we further investigated and compared other parameters associated with hyperglycemia including $\boldsymbol{\alpha}$ - and $\beta$-cell mass, plasma insulin and glucagon concentrations, and functional response via glucose-coupled hormone secretion. Such parameters were studied to determine how these factors were related to the differential development of hyperglycemia across the two genotypes.

First, we investigated the impact of STZ on $\beta$ - and $\alpha$-cell mass in both WT and UCP2KO mice to determine whether the reduced susceptibility to hyperglycemia development in UCP2-deficient mice observed in Fig. 1 was the result of altered STZ-induced $\beta$-cell toxicity. MLDS injections significantly reduced $\beta$-cell mass in both WT and UCP2KO islets, similarly (Fig. 2). Additionally, no impact on $\boldsymbol{\alpha}$-cell mass was observed after MLDS when compared to the untreated controls (Fig. 3). Together, these data confirm that the toxicity of STZ is specific to $\beta$-cells and that the reduced sensitivity of UCP2KO to STZ-induced hyperglycemia is not the result of altered sensitivity of UCP2KO $\beta$-cells to the toxic effects of STZ.

In addition to islet cell mass, we also measured plasma insulin and glucagon levels in both genotypes to determine if circulating hormone levels were a contributing factor to the observed difference in STZ-induced hyperglycemia 
development. In the WT animals, plasma insulin was significantly reduced, while plasma glucagon levels were significantly increased after 14-day MLDS treatment (Fig. 4), which has been demonstrated previously in other studies (Levy et al. 1984, Fiebig et al. 2001). However, in the UCP2KO animals, no significant reduction in plasma insulin was observed after STZ treatment. These UCP2-deficient mice even maintained higher plasma insulin levels after STZ than WT animals after STZ. Given the propensity for UCP2KO animals to secrete more insulin, it is likely that their elevated insulin levels contributed to a resistance against STZ-induced hyperglycemia perhaps via enhanced glucose utilization. Unlike the WT, plasma glucagon levels remained unchanged after STZ treatment in the UCP2KO. Plasma glucagon levels were significantly lower in the STZ-treated UCP2KO animals than the STZ-treated WT animals. Decreased glucagon may also be partially attributed to the elevated insulin found in UCP2KO, since insulin exerts an inhibitory paracrine effect on $\alpha$-cells (Ishihara et al. 2003, Xu et al. 2006). Both higher plasma insulin and lower plasma glucagon levels in the UCP2KO animals support their resistance to STZ-induced hyperglycemia.

It is important to mention that the specific UCP2KO mouse model used in this study (C57BL6/129 mixed background; Zhang et al. 2001) has recently been put into contention by a report from $\mathrm{Pi}$ et al. (2009). In their study, thorough back-crossing of their UCP2KO mouse (Arsenijevic et al. 2000) led to decreased insulin secretion, which was attributed to oxidative stress. Interestingly, such results were in contrast to our reports showing a correlation between UCP2KO mice and enhanced $\beta$-cell function (Zhang et al. 2001, Joseph et al. 2002). Pi et al. suggest that genetic background affected the phenotype of the UCP2KO mice used in various studies linking UCP2 to $\beta$-cell function. The specific differences in the mouse models remain to be elucidated; however, as the manipulation of UCP2 by other means, such as adenoviral overexpression (Chan et al. 1999), anti-sense knockdown (De Souza et al. 2007), or pharmacological inhibition (Zhang et al. 2006) have all demonstrated UCP2 to be a negative modulator of insulin secretion, in agreement with the original findings of the C57BL6/ 129 mixed background UCP2KO mouse model (Zhang et al. 2001).

\section{Knockout of UCP2 impairs $\alpha$-cell function and contributes to resistance to $S T Z$-induced hyperglycemia}

While the plasma insulin and glucagon levels support the extent of hyperglycemia development in both genotypes, they do not tell us how STZ affects $\alpha$ - and $\beta$-cell function and what impact UCP2 has on these STZ-mediated effects. As such, glucose-coupled insulin and glucagon secretion were measured and compared in WT and UCP2KO islets in vitro after STZ exposure for $16 \mathrm{~h}$. Our results showed that STZ treatment of WT islets did not result in impaired GSIS, despite reduced plasma insulin levels and reduced $\beta$-cell mass.
Many studies of STZ in mouse and rat islets demonstrate a significant reduction in GSIS after STZ (for review see Szkudelski (2001) and Lenzen (2008)). We attribute this difference to the fact that our studies were done in vitro on isolated islets treated with STZ for $16 \mathrm{~h}$. Removal of the islets and hence disconnection from its microvasculature could have impaired the delivery of STZ to the interior of the islets and thus to the $\beta$-cells. However, what is clear from these experiments is that UCP2-deficient control islets displayed a significant increase in GSIS, which was reduced to levels similar to that of WT after STZ treatment. The large induction of GSIS in control UCP2-deficient islets is in line with previous findings which demonstrate a similar phenomenon (Chan et al. 1999, Zhang et al. 2001, Joseph et al. 2002, Saleh et al. 2006) and has been attributed to increased levels of ATP production as a result of lack of mitochondrial uncoupling, leading to improved insulin secretion. However, after STZ treatment, we observed a significant decrease in GSIS in the UCP2KO compared to the control, bringing GSIS to a level similar to that observed in the WT. Interestingly, the mechanism of action of STZ causes depletion of $\mathrm{NAD}^{+}$stores as a result of constitutive activation of DNA repair mechanisms (Heller et al. 1994). This depletion of $\mathrm{NAD}^{+}$leads to depletion of ATP stores. Despite having reduced mitochondrial uncoupling as a result of UCP2 deletion, the reduction of ATP by STZ trumps the deletion of UCP2, thereby reducing the ability to secrete insulin when stimulated with glucose. This suggests that, in the $\beta$-cell, the improvement of function observed in UCP2deficient islets is dependent upon increased levels of ATP production as a direct result of reduced mitochondrial uncoupling. However, this does not appear to be the case in the $\alpha$-cell (see below).

To asses $\boldsymbol{\alpha}$-cell function, we measured glucose-regulated glucagon secretion (GRGS). We found significantly reduced glucagon secretion in the UCP2KO compared with that of the WT, both in the control and in the STZ-treated UCP2KO islets (Fig. 5B). This reduced glucagon secretion in the UCP2KO can be explained by two possible mechanisms. In the first, the high level of insulin secretion from the control (untreated) UCP2KO $\beta$-cell may impair glucagon secretion in the $\alpha$-cell due to a paracrine inhibitory effect (Ishihara et al. 2003). However, if paracrine inhibition was the sole reason for the reduced GRGS observed in the UCP2KO, then we would expect to observe a significant increase in GRGS after STZ treatment as a result of reduced GSIS in this condition. Interestingly, we did not observe a significant increase in glucagon secretion after STZ treatment despite reduced insulin secretion. Therefore, we further suggest that knockout of UCP2 itself leads to impairment of $\boldsymbol{\alpha}$-cell function and reduced glucagon secretion, contributing to resistance to hyperglycemia development in response to STZ. This finding is supported by a recent study by Diao et al. (2008), who demonstrated that UCP2 was more highly expressed in the $\alpha$-cell than the $\beta$-cell and showed a direct role for UCP2 in maintaining $\alpha$-cell function at the level of 
glucose metabolism, glucagon secretion, and cytoprotection (Diao et al. 2008). While the mechanism of glucagon secretion is still a matter of debate, it has recently been hypothesized that glucagon secretion operates using similar 'machinery' as insulin secretion; however, in the $\alpha$-cell, ATPinduced inhibition of the $\mathrm{K}_{\mathrm{ATP}}$ channel can result in inactivation of voltage-dependent calcium channels which are coupled to glucagon secretion (MacDonald et al. 2007). Interestingly, Diao et al. (2008) showed that $\alpha$-cells from UCP2KOs have higher levels of ATP, which at least in part could explain the deficiency in glucagon secretion.

\section{Knockout of UCP2 chronically elevates cellular ROS levels, particularly in the $\alpha$-cell, altering cell proliferation and potentially cell signaling}

Currently, there are several hypotheses regarding the physiological function(s) of UCP2. Many of the studies carried out till date have focused on the potential uncoupling function of UCP2 and its impact on ATP production and hormone secretion. However, in conjunction with its uncoupling function, UCP2 is also thought to mediate mitochondrial ROS production. Several recent studies have demonstrated that UCP2 acts as a modulator of ROS production in various tissues (Anedda et al. 2008, Degasperi et al. 2008, Giardina et al. 2008). Interestingly, UCP2 has been shown to be activated by ROS molecules themselves (Echtay et al. 2002, Krauss et al. 2003), potentially representing a feedback loop whereby UCP2 senses mitochondrial ROS and upregulates its expression in an attempt to decrease high ROS production (Giardina et al. 2008). Classically, ROS were observed as harmful and toxic byproducts of cellular metabolism. However, more recently, ROS have been recognized as important signaling molecules, which regulate many vital cellular functions. As such, we measured and compared ROS levels, more specifically $\mathrm{H}_{2} \mathrm{O}_{2}$, in $\alpha$ - and $\beta$-cells isolated from WT and UCP2KO before and after $16 \mathrm{~h} \mathrm{STZ} \mathrm{treatment.}$

To measure ROS in $\beta$-cells, we dispersed islets into individual cells and quantified cellular ROS using the $\mathrm{H}_{2} \mathrm{O}_{2-}$ sensitive fluorescent dye DCF in large cells ( $\beta$-cells are often larger in comparison to other cell types in dispersed islets; Diao et al. 2008). We observed higher basal ROS levels in $\beta$-cells from UCP2KO mice than in WT (Fig. 6A). To estimate ROS in $\alpha$-cells we imaged whole islets loaded with DCF. Confocal microscopy demonstrated that DCF fluorescence was not penetrable beyond the outer layer of the cells of the islets (not shown), which in the mouse is comprised mainly of $\alpha$-cells (Gromada et al. 2007). Similar to that of $\beta$-cells, however, much more dramatic, we found that UCP2KO $\boldsymbol{\alpha}$-cells have significantly higher basal ROS levels than WT (Fig. 6B). Together, our findings of higher basal cellular ROS levels in $\alpha$ - and $\beta$-cells confirm that of other studies where UCP2KO also increased basal ROS levels in islets (Krauss et al. 2003, Joseph et al. 2004) and macrophages (Arsenijevic et al. 2000, Bai et al. 2005). Interestingly, exposure to low levels of ROS is thought not to mediate cytotoxic events, but rather activate signal transduction pathways important for cell growth and function. Low exposure to $\mathrm{H}_{2} \mathrm{O}_{2}$ has been shown to activate $\mathrm{NF}-\kappa \mathrm{B} / \mathrm{rel}$, AP-1, and MAPKs (Powis et al. 1997). Oxidants can stimulate receptor tyrosine kinases even in the absence of an activator ligand, as well as downstream signal transduction pathways including protein kinase C, c-jun-terminal kinase and ras (Staal et al. 1994, Kamata \& Hirata 1999, Liou et al. 2000). Interestingly, MAPK pathway activation in UCP2KO mice macrophages is quicker and stronger than in their WT littermates (Emre et al. 2007b). It is also well accepted that low levels of ROS exposure can promote cell proliferation (Finkel 2000). In support of this, we have not only shown that knockdown of UCP2 results in greater basal ROS production, but we have also shown that UCP2KO mice displayed greater $\alpha$ - and $\beta$-cell mass. Interestingly, UCP2KO mice fed a high-fat diet were shown to have increased insulin secretory capacity as a result of increased pancreatic $\beta$-cell mass (Joseph et al. 2002). We later demonstrated that UCP2KO islets have higher basal ROS levels (Joseph et al. 2004). Therefore, we hypothesize that higher basal ROS levels in the UCP2KO islets could contribute to constitutive activation of ROS-signaling pathways leading to greater cell proliferation as well as altered cellular functions.

It has been well-documented that knockout of UCP2 results in improved insulin secretion (Zhang et al. 2001, Joseph et al. 2002, 2004, Saleh et al. 2006, De Souza et al. 2007, Affourtit \& Brand 2008). In these studies, the role of UCP2 as an UCP uncoupled and its impact on ATP production are the central focus. A recent study has demonstrated that insulin secretion is affected by the level of cellular ROS (Pi et al. 2007). That is, higher ROS levels improve insulin secretion. This finding is in line with our study where we demonstrate that higher ROS in the UCP2KO $\beta$-cell correlates well with improved insulin secretion. Additionally, we also observe lower glucagon secretion in these UCP2-deficient islets, which is maintained after STZ application and we believe is a contributing factor to the resistance of hyperglycemia development in these animals after STZ administration. Currently, there is little to no literature on the impact of high ROS levels on glucagon secretion, however, we propose two possible scenarios. First, it is possible that the improved insulin secretion observed in these UCP2-deficient islets increases the paracrine effect on the $\alpha$-cell resulting in lower glucagon secretion. The second possibility is that higher basal cellular ROS in these cells directly impairs $\boldsymbol{\alpha}$-cell glucagon secretion. Recall that after STZ treatment, we did not observe improved glucagon secretion despite reduced insulin secretion and its paracrine effect in the UCP2KO islet; therefore, we suggest that chronically increased basal ROS signaling as a result of UCP2 depletion in the islet not only alters proliferative pathways leading to increased $\alpha$ - and $\beta$-cell mass, but also directly impairs the mechanism of glucagon secretion contributing to the lesser development of hyperglycemia in the UCP2KO mice after STZ administration. 
In this study, we set out to investigate the impact of UCP2 on the development of STZ-induced diabetes. We found that UCP2-deficiency led to a resistance towards hyperglycemia development in response to STZ, which was associated with higher plasma insulin and lower plasma glucagon levels. Chronically elevated basal cellular ROS formation in UCP2-deficient $\alpha$ - and $\beta$-cells appeared to have opposing impacts on $\alpha$ - and $\beta$-cell functions. Higher ROS in UCP2-deficient $\beta$-cells was associated with improved GSIS; however, higher ROS in UCP2-deficient $\alpha$-cells was associated with impaired GRGS. This impairment of $\alpha$-cell function was maintained post-STZ administration, suggesting that UCP2-deficient mice develop lesser hyperglycemia than their WT counterparts in response to STZ-induced diabetes as a result of reduced glucagon secretion/ $\alpha$-cell function. Currently, there is significant evidence to suggest that hyperglucagonemia plays a role in the development of hyperglycemia in type 2 diabetes (Gromada et al. 2007). As such, it will be important to determine the signaling events that link UCP2 to glucagon secretion and $\alpha$-cell function. Given the results from this study, the role of UCP2 in the regulation of ROS production and ROS signaling may be an important contributing factor.

\section{Declaration of interest}

The authors declare that there is no conflict of interest that would prejudice the impartiality of this scientific work.

\section{Funding}

This work was funded by the CIHR MOP-12898 to M B W, a Banting and Best Diabetes Centre Post-doctoral Fellowship (C A R-D) and a Banting and Best Diabetes Centre Graduate Studentship (S C L).

\section{Acknowledgements}

We wish to thank E M Allister and F F Dai for their insightful input into this manuscript. Also, we would like to thank J W Scholey for assistance with the streptozotocin treatments.

\section{References}

Affourtit C \& Brand MD 2008 Uncoupling protein-2 contributes significantly to high mitochondrial proton leak in INS-1E insulinoma cells and attenuates glucose-stimulated insulin secretion. Biochemical Journal 409 199-204.

Anedda A, Rial E \& Gonzalez-Barroso MM 2008 Metformin induces oxidative stress in white adipocytes and raises uncoupling protein 2 levels. Journal of Endocrinology 199 33-40.

Arsenijevic D, Onuma H, Pecqueur C, Raimbault S, Manning BS, Miroux B, Couplan E, Alves-Guerra MC, Goubern M, Surwit R et al. 2000 Disruption of the uncoupling protein-2 gene in mice reveals a role in immunity and reactive oxygen species production. Nature Genetics $\mathbf{2 6}$ $435-439$.
Asghar Z, Yau D, Chan F, Leroith D, Chan CB \& Wheeler MB 2006 Insulin resistance causes increased beta-cell mass but defective glucose-stimulated insulin secretion in a murine model of type 2 diabetes. Diabetologia 49 90-99.

Bai Y, Onuma H, Bai X, Medvedev AV, Misukonis M, Weinberg JB, Cao W, Robidoux J, Floering LM, Daniel KW et al. 2005 Persistent nuclear factorkappa $\mathrm{B}$ activation in $\mathrm{Ucp} 2-/-$ mice leads to enhanced nitric oxide and inflammatory cytokine production. Journal of Biological Chemistry $\mathbf{2 8 0}$ 19062-19069.

Chan CB, MacDonald PE, Saleh MC, Johns DC, Marban E \& Wheeler MB 1999 Overexpression of uncoupling protein 2 inhibits glucose-stimulated insulin secretion from rat islets. Diabetes 48 1482-1486.

Chan CB, De Leo D, Joseph JW, McQuaid TS, Ha XF, Xu F, Tsushima RG, Pennefather PS, Salapatek AM \& Wheeler MB 2001 Increased uncoupling protein-2 levels in beta-cells are associated with impaired glucosestimulated insulin secretion: mechanism of action. Diabetes 50 1302-1310.

Degasperi GR, Romanatto T, Denis RG, Araujo EP, Moraes JC, Inada NM, Vercesi AE \& Velloso LA 2008 UCP2 protects hypothalamic cells from TNF-alpha-induced damage. FEBS Letters 582 3103-3110.

Diao J, Asghar Z, Chan CB \& Wheeler MB 2005 Glucose-regulated glucagon secretion requires insulin receptor expression in pancreatic alpha-cells. Journal of Biological Chemistry 280 33487-33496.

Diao J, Allister EM, Koshkin V, Lee SC, Bhattacharjee A, Tang C, Giacca A, Chan CB \& Wheeler MB 2008 UCP2 is highly expressed in pancreatic alpha-cells and influences secretion and survival. PNAS 105 12057-12062.

Dubuc PU 1987 Hormonal responses during development of streptozotocin diabetes in rats. Endocrinologia Experimentalis 21 275-284.

Echtay KS, Roussel D, St-Pierre J, Jekabsons MB, Cadenas S, Stuart JA, Harper JA, Roebuck SJ, Morrison A, Pickering S et al. 2002 Superoxide activates mitochondrial uncoupling proteins. Nature 415 96-99.

Echtay KS, Esteves TC, Pakay JL, Jekabsons MB, Lambert AJ, Portero-Otin M, Pamplona R, Vidal-Puig AJ, Wang S, Roebuck SJ et al. 2003 A signalling role for 4-hydroxy-2-nonenal in regulation of mitochondrial uncoupling. EMBO Journal 22 4103-4110.

Emre Y, Hurtaud C, Karaca M, Nubel T, Zavala F \& Ricquier D 2007a Role of uncoupling protein UCP2 in cell-mediated immunity: how macrophage-mediated insulitis is accelerated in a model of autoimmune diabetes. PNAS 104 19085-19090.

Emre Y, Hurtaud C, Nubel T, Criscuolo F, Ricquier D \& Cassard-Doulcier AM $2007 b$ Mitochondria contribute to LPS-induced MAPK activation via uncoupling protein UCP2 in macrophages. Biochemical Journal $\mathbf{4 0 2}$ 271-278.

Fiebig RG, Hollander JM \& Ji LL 2001 Exercise down-regulates hepatic fatty acid synthase in streptozotocin-treated rats. Journal of Nutrition 131 2252-2259.

Fink BD, Hong YS, Mathahs MM, Scholz TD, Dillon JS \& Sivitz WI 2002 UCP2-dependent proton leak in isolated mammalian mitochondria. Journal of Biological Chemistry 277 3918-3925.

Finkel T 2000 Redox-dependent signal transduction. FEBS Letters $\mathbf{4 7 6}$ $52-54$.

Fleury C, Neverova M, Collins S, Raimbault S, Champigny O, Levi-Meyrueis C, Bouillaud F, Seldin MF, Surwit RS, Ricquier D et al. 1997 Uncoupling protein-2: a novel gene linked to obesity and hyperinsulinemia. Nature Genetics 15 269-272.

Giardina TM, Steer JH, Lo SZ \& Joyce DA 2008 Uncoupling protein-2 accumulates rapidly in the inner mitochondrial membrane during mitochondrial reactive oxygen stress in macrophages. Biochimica et Biophysica Acta 1777 118-129.

Gopaul NK, Anggard EE, Mallet AI, Betteridge DJ, Wolff SP \& NouroozZadeh J 1995 Plasma 8-epi-PGF2 alpha levels are elevated in individuals with non-insulin dependent diabetes mellitus. FEBS Letters 368 225-229.

Göpel S, Kanno T, Barg S, Galvanovskis J \& Rorsman P 1999 Voltage-gated and resting membrane currents recorded from B-cells in intact mouse pancreatic islets. Journal of Physiology 521 717-728.

Grankvist K, Marklund SL \& Taljedal IB 1981 CuZn-superoxide dismutase, $\mathrm{Mn}$-superoxide dismutase, catalase and glutathione peroxidase in pancreatic islets and other tissues in the mouse. Biochemical Journal 199 393-398. 
Gromada J, Ma X, Hoy M, Bokvist K, Salehi A, Berggren PO \& Rorsman P 2004 ATP-sensitive $\mathrm{K}^{+}$channel-dependent regulation of glucagon release and electrical activity by glucose in wild-type and SUR $1-/-$ mouse alpha-cells. Diabetes 53 181-189.

Gromada J, Franklin I \& Wollheim CB 2007 Alpha-cells of the endocrine pancreas: 35 years of research but the enigma remains. Endocrine Reviews $\mathbf{2 8}$ 84-116.

Heller B, Burkle A, Radons J, Fengler E, Jalowy A, Muller M, Burkart V \& Kolb H 1994 Analysis of oxygen radical toxicity in pancreatic islets at the single cell level. Biological Chemistry Hoppe-Seyler 375 597-602.

Ishihara H, Maechler P, Gjinovci A, Herrera PL \& Wollheim CB 2003 Islet beta-cell secretion determines glucagon release from neighbouring alphacells. Nature Cell Biology 5 330-335.

Joseph JW, Koshkin V, Zhang CY, Wang J, Lowell BB, Chan CB \& Wheeler MB 2002 Uncoupling protein 2 knockout mice have enhanced insulin secretory capacity after a high-fat diet. Diabetes 51 3211-3219.

Joseph JW, Koshkin V, Saleh MC, Sivitz WI, Zhang CY, Lowell BB, Chan CB \& Wheeler MB 2004 Free fatty acid-induced beta-cell defects are dependent on uncoupling protein 2 expression. Journal of Biological Chemistry 279 51049-51056.

Kamata H \& Hirata H 1999 Redox regulation of cellular signalling. Cellular Signalling 11 1-14.

Krauss S, Zhang CY, Scorrano L, Dalgaard LT, St-Pierre J, Grey ST \& Lowell BB 2003 Superoxide-mediated activation of uncoupling protein 2 causes pancreatic beta cell dysfunction. Journal of Clinical Investigation 112 1831-1842.

Lenzen S 2008 The mechanisms of alloxan- and streptozotocin-induced diabetes. Diabetologia 51 216-226.

Lenzen S, Drinkgern J \& Tiedge M 1996 Low antioxidant enzyme gene expression in pancreatic islets compared with various other mouse tissues. Free Radical Biology \& Medicine 20 463-466.

Levy J, Gavin JR III, Faust A, Gingerich RL \& Avioli LV 1984 Impaired insulin action in rats with non-insulin-dependent diabetes. Diabetes $\mathbf{3 3}$ 901-906.

Liou JS, Chen CY, Chen JS \& Faller DV 2000 Oncogenic ras mediates apoptosis in response to protein kinase $\mathrm{C}$ inhibition through the generation of reactive oxygen species. Journal of Biological Chemistry 275 39001-39011.

MacDonald PE, De Marinis YZ, Ramracheya R, Salehi A, Ma X, Johnson PR, Cox R, Eliasson L \& Rorsman P 2007 A K $^{\text {ATP }}$ channeldependent pathway within alpha cells regulates glucagon release from both rodent and human islets of Langerhans. PLoS Biology 5 e143.

Maechler P, Jornot L \& Wollheim CB 1999 Hydrogen peroxide alters mitochondrial activation and insulin secretion in pancreatic beta cells. Journal of Biological Chemistry 274 27905-27913.

Malaisse WJ, Malaisse-Lagae F, Sener A \& Pipeleers DG 1982 Determinants of the selective toxicity of alloxan to the pancreatic B cell. PNAS 79 927-930.

Negre-Salvayre A, Hirtz C, Carrera G, Cazenave R, Troly M, Salvayre R, Penicaud L \& Casteilla L 1997 A role for uncoupling protein-2 as a regulator of mitochondrial hydrogen peroxide generation. FASEB Journal 11 809-815.

Nourooz-Zadeh J, Tajaddini-Sarmadi J, McCarthy S, Betteridge DJ \& Wolff SP 1995 Elevated levels of authentic plasma hydroperoxides in NIDDM. Diabetes 44 1054-1058.
O'Brien BA, Harmon BV, Cameron DP \& Allan DJ 1996 Beta-cell apoptosis is responsible for the development of IDDM in the multiple low-dose streptozotocin model. Journal of Pathology 178 176-181.

Pi J, Bai Y, Zhang Q, Wong V, Floering LM, Daniel K, Reece JM, Deeney JT, Andersen ME, Corkey BE et al. 2007 Reactive oxygen species as a signal in glucose-stimulated insulin secretion. Diabetes 56 1783-1791.

Pi J, Bai Y, Daniel KW, Liu D, Lyght O, Edelstein D, Brownlee M, Corkey BE \& Collin S 2009 Persistent oxidative stress due to absence of uncoupling protein 2 associated with impaired pancreatic $\beta$-cell function. Endocrinology 150 3040-3048.

Powis G, Gasdaska JR \& Baker A 1997 Redox signaling and the control of cell growth and death. Advances in Pharmacology 38 329-359.

Rakieten N, Rakieten ML \& Nadkarni MV 1963 Studies on the diabetogenic action of streptozotocin (NSC-37917). Cancer Chemotherapy Reports 29 91-98.

Rehman A, Nourooz-Zadeh J, Moller W, Tritschler H, Pereira P \& Halliwell B 1999 Increased oxidative damage to all DNA bases in patients with type II diabetes mellitus. FEBS Letters 448 120-122.

Saleh MC, Wheeler MB \& Chan CB 2006 Endogenous islet uncoupling protein-2 expression and loss of glucose homeostasis in ob/ob mice. Journal of Endocrinology 190 659-667.

De Souza CT, Araujo EP, Stoppiglia LF, Pauli JR, Ropelle E, Rocco SA, Marin RM, Franchini KG, Carvalheira JB, Saad MJ et al. 2007 Inhibition of UCP2 expression reverses diet-induced diabetes mellitus by effects on both insulin secretion and action. FASEB Journal 21 1153-1163.

Staal FJ, Anderson MT, Staal GE, Herzenberg LA \& Gitler C 1994 Redox regulation of signal transduction: tyrosine phosphorylation and calcium influx. PNAS 91 3619-3622.

Szkudelski T 2001 The mechanism of alloxan and streptozotocin action in B cells of the rat pancreas. Physiological Research 50 537-546.

Tiedge M, Lortz S, Drinkgern J \& Lenzen S 1997 Relation between antioxidant enzyme gene expression and antioxidative defense status of insulin-producing cells. Diabetes 46 1733-1742.

Xu E, Kumar M, Zhang Y, Ju W, Obata T, Zhang N, Liu S, Wendt A, Deng S, Ebina $Y$ et al. 2006 Intra-islet insulin suppresses glucagon release via GABA-GABAA receptor system. Cell Metabolism 3 47-58.

Zhang CY, Baffy G, Perret P, Krauss S, Peroni O, Grujic D, Hagen T, Vidal-Puig AJ, Boss O, Kim YB et al. 2001 Uncoupling protein-2 negatively regulates insulin secretion and is a major link between obesity, beta cell dysfunction, and type 2 diabetes. Cell $105745-755$.

Zhang CY, Parton LE, Ye CP, Krauss S, Shen R, Lin CT, Porco JA Jr \& Lowell BB 2006 Genipin inhibits UCP2-mediated proton leak and acutely reverses obesity- and high glucose-induced $\beta$ cell dysfunction in isolated pancreatic islets. Cell Metabolism 3 417-427.

Received in final form 19 July 2009

Accepted 27 July 2009

Made available online as an Accepted Preprint 27 July 2009 